\title{
Effect of Electric Field Distribution on the Morphologies of Laser-Induced Damage in Hafnia-Silica Multilayer Polarizers
}

\author{
F. Y. Génin, C. J. Stolz, T. Reitter, \\ M. R. Kozlowski, R. P. Bevis, \\ and $M$. K. vonGunten
}

This paper was prepared for submittal to the 28th Annual Symposium on Optical Materials

for High Power Lasers

Boulder, Colorado

October 7-9, 1996

January 24, 1997

This is a preprint of a paper intended for publication in a journal or proceedings. Since changes may be made before publication, this preprint is made available with the understanding that it will not be cited or reproduced without the permission of the author. 


\section{DISCLAIMER}

This document was prepared as an account of work sponsored by an agency of the United States Government. Neither the United States Government nor the University of California nor any of their employees, makes any warranty, express or implied, or assumes any legal liability or responsibility for the accuracy, completeness, or usefulness of any information, apparatus, product, or process

disclosed, or represents that its use would not infringe privately owned rights. Reference herein to any specific commercial product, process, or service by trade name, trademark, manufacturer, or otherwise, does not necessarily constitute or imply its endorsement, recommendation, or favoring by the United States Government or the University of California. The views and opinions of authors expressed herein do not necessarily state or reflect those of the United States Government or the University of California, and shall not be used for advertising or product endorsement purposes. 


\title{
Effect of electric field distribution on the morphologies of laser-induced damage in hafnia-silica multilayer polarizers
}

\author{
F. Y. Génina) , C. J. Stolz, T. Reitter, M. R. Kozlowski \\ Lawrence Livermore National Laboratory \\ Livermore, California 94550 \\ R. P. Bevis, and M. K. vonGunten \\ Spectra-Physics Lasers, Inc. \\ Mountain View, California 94943.
}

\begin{abstract}
Hafnia-silica multilayer polarizers were deposited by e-beam evaporation onto BK7 glass substrates. The polarizers were designed to operate at a wavelength of $1064 \mathrm{~nm}$ at Brewster's angle $\left(56^{\circ}\right)$. The polarizers were tested with a 3 -ns laser pulse at $45^{\circ}, 56^{\circ}$, and $65^{\circ}$ incidence angle in order to vary the electric field distribution in the multilayer, study their effects on the damage morphology, and investigate the possible advantages of off-use angle laser conditioning. The morphology of the laser-induced damage was characterized by optical and scanning electron microscopy. Four distinct damage morphologies (pit, flat bottom pit, scald, and outer layer delamination) were observed. These damage morphologies were found to depend strongly on the angle of incidence of the laser beam. In particular, massive delamination observed at $45^{\circ}$ and $56^{\circ}$ incidence, did not occur at $65^{\circ}$. Instead, large and deep pits were found at $65^{\circ}$. The electric field distribution, the temperature rise and the change in stress in the multilayer were calculated to attempt to better understand the relationship between damage morphology, electric field peak locations, and maximum thermal stress gradients. The calculations showed a two-fold increase in stress change in the hafnia top layers depending on the incidence angle. The stress gradient in the first hafnia-silica interface was found to be highest for $45^{\circ}, 56^{\circ}$, and $65^{\circ}$, respectively. Finally, the maximum stress was deeper in the multilayer at $65^{\circ}$. Although the limitations of such simple thermal mechanical model are obvious, the results can explain that outer layer delamination is more likely at $45^{\circ}$ and $56^{\circ}$ than $65^{\circ}$ and that damage sites are expected to be deeper at $65^{\circ}$.
\end{abstract}

Keywords: laser-induced damage, hafnia-silica polarizers, damage morphology, laser conditioning, $1064 \mathrm{~nm}$, electric field distribution, stress gradients, beam incidence angle.

\section{INTRODUCTION}

This work has been motivated by the necessity to improve the damage threshold of mirrors and polarizers used for high fluence fusion laser applications such as the National Ignition Facility (NIF) at Lawrence Livermore National Laboratory (LLNL) or the Laser Mégajoules in France. The subject of laser-induced damage of coated optics has been extensively studied in the last four decades. Significant efforts have been devoted to relating the damage threshold to a variety of parameters such as film material, ${ }^{1-4}$ coatings design, ${ }^{5-8}$ laser wavelength, ${ }^{2,9,10}$ and pulse length. ${ }^{2,11-15}$ The relationship between damage morphology and damage growth has also been studied in detail. ${ }^{16}$ It is known that for hafnia-silica multilayer mirrors, four different morphologies can be found; pits, flat bottom pits, scalds and delaminates. ${ }^{17-20}$ Other studies published in these proceedings show that the delaminate is the most unstable morphology among the four ${ }^{16}$ and that the addition of a

a) Electronic Mail: fgenin@1lnl.gov 
thicker silica overcoat tends to eliminate such damage morphology thereby substantially improving their functional damage threshold. ${ }^{21}$

The angular dependence of damage threshold for mirrors has been studied by Newnam et al. for a $351 \mathrm{~nm}, 10-\mathrm{ns}$ laser. ${ }^{6,7}$ In Newnam's experiments, the coating design was modified to produce mirrors that reflect at different angles. The mirrors were tested at useangle. The tests showed that the higher the angle of incidence, the lower the damage threshold. In the present study, the polarizers were designed to operate at $56^{\circ}$ only. They were then tested at various angles of incidence. The goal was to investigate alternative methods to prevent delamination by less standard laser-conditioning without modifying the coatings design. The experiments were designed to understand if the damage threshold could be improved by conditioning polarizers at non-use angle of incidence. The idea was prompted by models of the thermal mechanical response of hafnia-silica multilayers which showed that the interaction between the multilayer and the laser light was influenced by the light incidence angle. The experiments were also designed to understand the effect of the electric field distribution in the multilayer stack on the damage morphology.

The article will first summarize the sample preparation method and the laser testing procedure. The calculated electric field distribution in a defect free multilayer polarizer coating will then be presented. The resulting temperature profiles and stress changes at the end of the 3-ns pulse will also be shown. The calculations and damage tests were performed for three different angles $\left(45^{\circ}, 56^{\circ}\right.$, and $\left.65^{\circ}\right)$. Indeed, the polarizer was designed to operate at $56^{\circ}$ at $1064 \mathrm{~nm}$; as explained earlier, varying the angle of incidence of the beam is an artificial way of changing the electric field peak intensity location in the multilayer stack. The damage test results will finally be discussed. In particular, the number of damage sites and their maximum diameter will be plotted as a function of the peak fluence of the beam. The morphological nature of damage will be emphasized because of the strong relationship between damage type and optics survivability.

\section{EXPERIMENTS}

\subsection{Sample preparation}

Hafnia-silica multilayers polarizers were deposited at Spectra-Physics Lasers, Inc. by electron beam evaporation onto $50.5 \mathrm{~mm}$ diameter BK7 glass substrates. The coating thickness was monitored in situ by an optical monitor, switching materials by shuttering when the thickness conditions were met. All the polarizers were prepared during the same coating run. The optical multilayer was designed to reflect at an angle of $56^{\circ}$ and a wavelength of $1064 \mathrm{~nm}$ in s-polarization and transmit in p-polarization (see Fig. 1).

\subsection{Laser damage test conditions}

The laser damage tests were carried out using a 3-ns pulse from a $1064 \mathrm{~nm} \mathrm{Nd:YAG}$ laser. ${ }^{22}$ The laser was focused to provide a far field circular Gaussian beam with a diameter of $1.1 \mathrm{~mm}$ at $1 / \mathrm{e}^{2}$ of the maximum intensity. The beam profile was recorded for each shot and the peak fluence was computed. Each site was irradiated with a single laser pulse at fluences ranging from 5 to $45 \mathrm{~J} / \mathrm{cm}^{2}$. The tests were conducted in s-polarization at $45^{\circ}, 56^{\circ}$, and $65^{\circ}$. The sites were examined before and after irradiation by Nomarski and back light optical microscopy. Any damage larger than about $2 \mu \mathrm{m}$ was detected using this method. Further post damage characterization was conducted using scanning electron microscopy (SEM).

\section{ELECTRIC FIELD DISTRIBUTION IN A PERFECT MULTILAYER}

In order to understand the changes in damage morphologies for different beam incidence angles, the electric field in the polarizer was computed at $45^{\circ}, 56^{\circ}$ and $65^{\circ}$ using a thin film design software. ${ }^{23} \quad$ More elaborate calculations taking into account the electric 
field enhancements by nodular defects ${ }^{24,25}$ have also been performed. However, these more sophisticated calculations only apply to normal incidence.

The electric field distribution for s-polarization is shown in Fig. 2. The electric field in the multilayer stack decays less rapidly at $65^{\circ}$ than at $45^{\circ}$ or $56^{\circ}$. The electric field peaks in the first or second hafnia layer at $45^{\circ}$ and $56^{\circ}$. On the other hand, the maximum field intensity is located in the third hafnia layer at $65^{\circ}$. The maximum intensities normalized to the $56^{\circ}$ maximum intensity are 1.19 and 1.21 at $45^{\circ}$ and $65^{\circ}$, respectively.

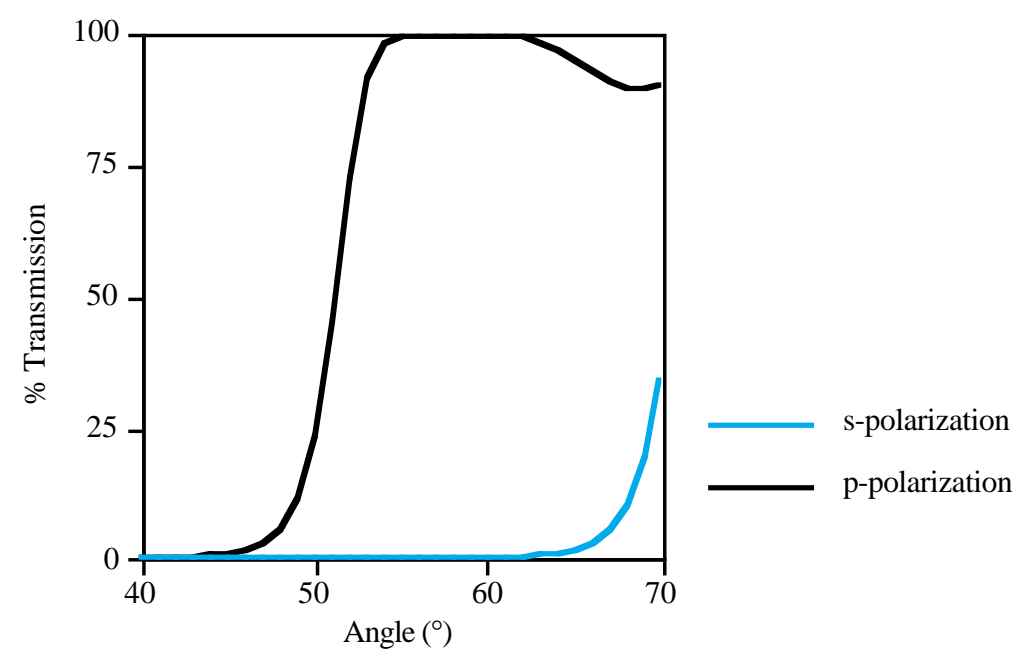

Fig. 1: Design optical performance in transmission of the polarizer in s- and p-polarization.

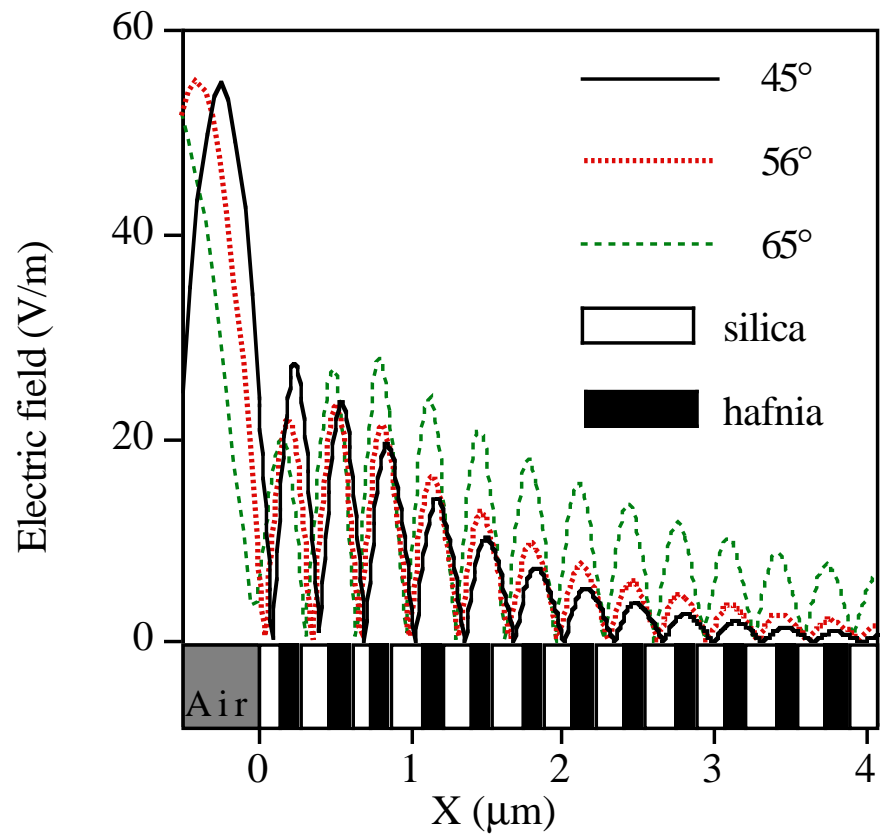

Fig. 2: Calculated standing wave electric field distribution for s-polarization in the multilayer polarizer designed for $56^{\circ}$ incidence at an angle of incidence of $45^{\circ}, 56^{\circ}$, and $65^{\circ}$. The fields are plotted for an input energy intensity of $1 \mathrm{~W} / \mathrm{m}^{2}$ measured using a detector placed normal to the beam direction. 


\section{TEMPERATURE AND STRESS FIELD DISTRIBUTIONS IN A PERFECT MULTILAYER}

Using the electric field distributions shown in Fig. 2, the volumetric heat generation rate, $\sigma \mathrm{E}^{2}$, and the transient thermal response were calculated for the three angles of incidence using the TOPAZ2D finite element code. ${ }^{26}$ Figure 3 shows the temperature profile at the end of the $3-\mathrm{ns}, 20 \mathrm{~J} / \mathrm{cm}^{2}$ laser pulse. As expected, the peak temperature rises are higher (by about a factor of 2) at off-design angle of incidence. It must be noted though that the temperature peaks occur at different locations for the three angles of incidence: the temperature is maximum in the first, second and third hafnia layer at $45^{\circ}, 56^{\circ}$ and $65^{\circ}$, respectively.

The temperature fields were subsequently used as input for mechanical response calculations using the NIKE2D finite element code ${ }^{27}$ and the parameters listed in Table 1 . Figure 4 illustrates the distribution of the quantity $\left(\sigma_{\max }-\sigma_{\min }\right)$ along the symmetry axis. This quantity is proportional to the stress intensity and is a commonly used parameter to estimate the failure of brittle materials. Here, the small axial stress change (tensile in the outer silica layers at early times, compressive everywhere by $t=20 \mathrm{~ns}$ ) is overwhelmed in magnitude by the compressive in-plane stresses in the outer hafnia layers. Finally, there is little stress change in the silica layers.

\begin{tabular}{|c|c|c|c|c|}
\hline Parameter & Unit & $\mathrm{SiO}_{2}$ & $\mathrm{HfO}_{2}$ & $\mathrm{BK} 7$ \\
\hline Thermal expansion coefficient & $\left(\mathrm{K}^{-1}\right)$ & $0.710^{-6}$ & $3.810^{-6}$ & $7.110^{-6}$ \\
\hline Thermal conductivity & $\left(\mathrm{W} . \mathrm{m}^{-1} . \mathrm{K}^{-1}\right)$ & 1.0 & 4.3 & 1.11 \\
\hline Young's modulus & $(\mathrm{G} . \mathrm{Pa})$ & 21 & 76 & 82 \\
\hline Density & $\left(\mathrm{kg} \cdot \mathrm{m}^{-5}\right)$ & 2,500 & 9,680 & 2,510 \\
\hline Heat capacity & $\left(\mathrm{J} . \mathrm{kg}^{-1} \cdot \mathrm{K}^{-1}\right)$ & 700 & 340 & 860 \\
\hline Poisson's ratio & - & 0.17 & $0.27\left(\mathrm{ZrO}_{2}\right)$ & 0.21 \\
\hline Loss tangent & $\left(\mathrm{Si}^{-1} \mathrm{~m}^{-1}\right)$ & 0.3366 & 1.1956 & - \\
\hline
\end{tabular}

Table 1: Materials properties of silica, hafnia and BK7 used for the numerical calculations of the thermal mechanical response of the multilayer stack.

The important result here is that most of the stress and temperature change occurs in the hafnia layer. The stress in the multilayer is maximum in the first, second and third hafnia layer at $45^{\circ}, 56^{\circ}$ and $65^{\circ}$, respectively. This may explain the reason for the tendency to delaminate at these two angles. On the other hand, the magnitude of the stress is much larger and deeper into the stack at $65^{\circ}$; this can explain that the polarizer shows very deep failure sites when tested at this angle. It is also important to note that the magnitude of the thermal stresses (i.e. between 10 and $20 \mathrm{MPa}$ ) seems still too small to predict failure. This is not very surprising since we have modeled a perfect multilayer with no nodules, voids, or adhesion problems between layers. Residual stresses generated during coating have also been ignored. Furthermore, the plasmas that often ignite on the surface of the coatings during laser illumination and the heat they can generate have not been taken into account. Finally, all the materials properties of the film material are still not known with a high degree of accuracy. 


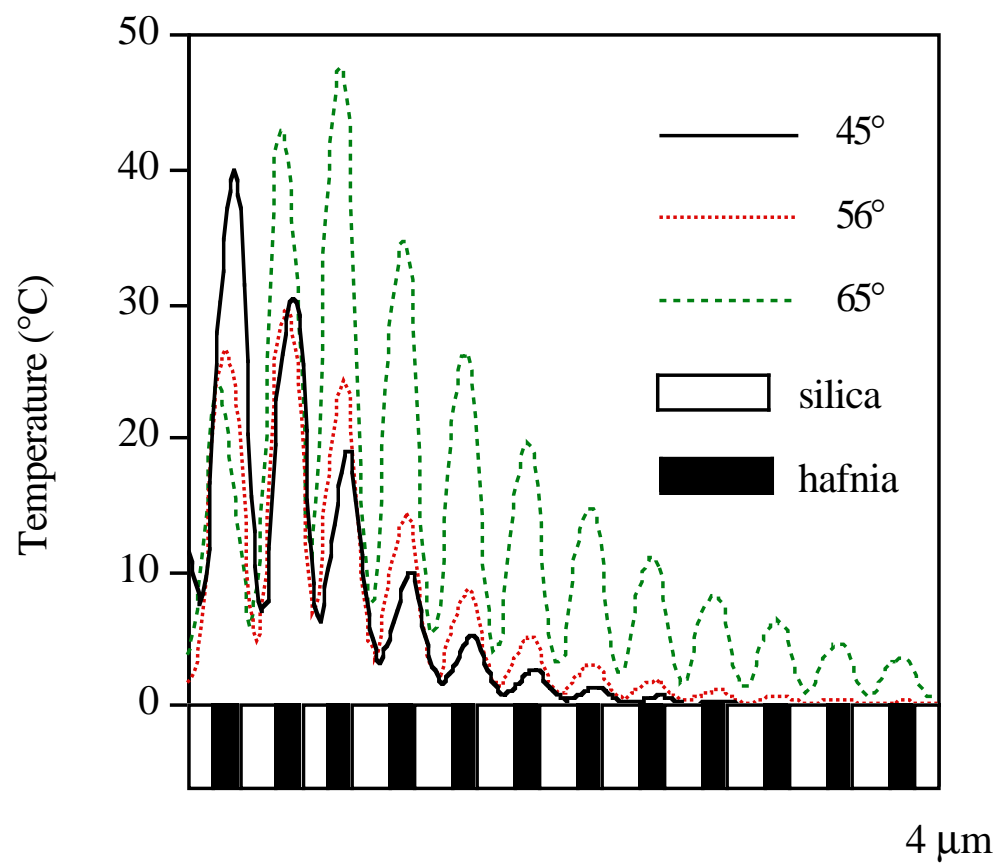

Fig. 3: Calculated temperature distribution in the polarizer for $45^{\circ}, 56^{\circ}$ and $65^{\circ}$ angle of incidence at the end of the 3-ns square laser pulse for an incident fluence of $20 \mathrm{~J} / \mathrm{cm}^{2}$. Only the first 12 layer pairs are represented on this figure.

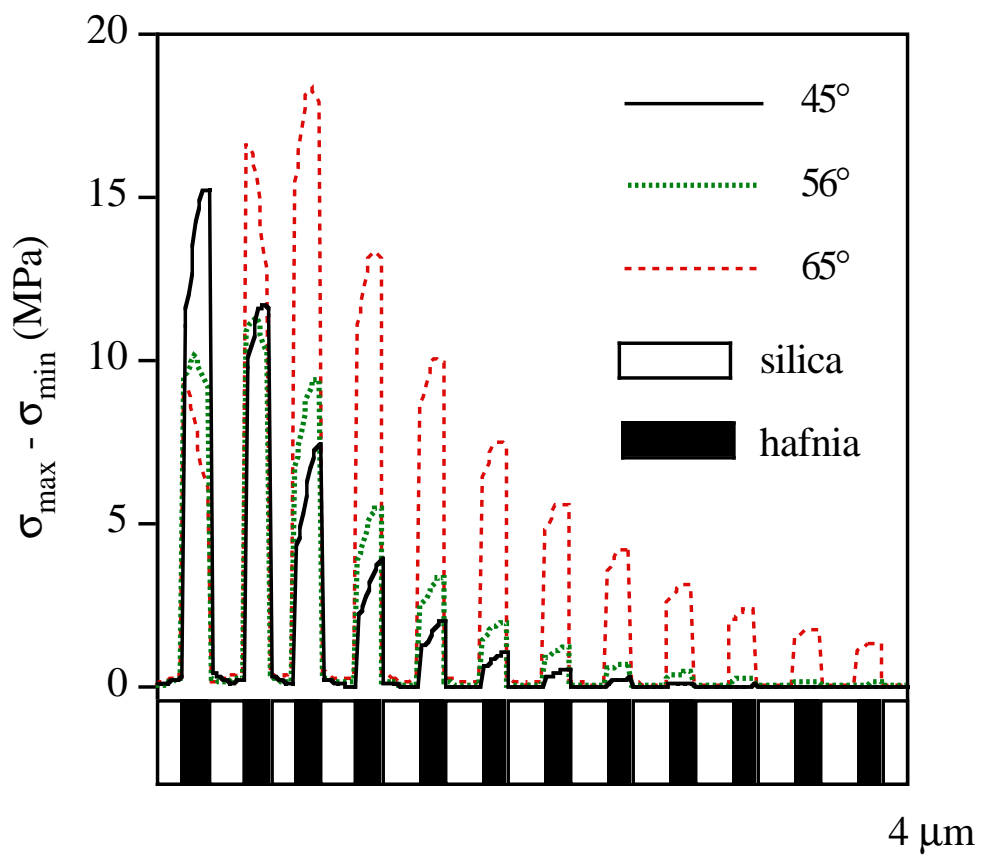

Fig. 4: Maximum principal stress (in-plane stress in this case) minus minimum principal stress (axial stress in this case) in the polarizer for $45^{\circ}, 56^{\circ}$ and $65^{\circ}$ angle of incidence at the end of the 3-ns square laser pulse for an incident fluence of $20 \mathrm{~J} / \mathrm{cm}^{2}$. 


\section{RESULTS}

\subsection{Damage morphologies:}

Four main damage morphologies are commonly found for hafnia-silica mirrors and polarizers at $1064 \mathrm{~nm}$ : pits, flat bottom pits, scalds and delaminates. ${ }^{17}$ Figure 5 shows optical micrographs of typical damaged areas after a shot at $45^{\circ}, 56^{\circ}$ and $65^{\circ}$. It is clear that delamination does not occur at $65^{\circ}$. Figure 6 shows a delaminate formed at $45^{\circ}$. The delamination footprint follows the shape of an expanding ellipse. The shape is believed to be caused by a plasma igniting during illumination and growing up the beam. Figure 7 shows the details of a delaminate formed at $56^{\circ}$. Close inspection clearly indicates that only the top silica layer is removed. Finally, Fig. 8 shows the details of the damage morphology at $65^{\circ}$. The pits are much deeper as suggested by the number of layers that can be counted on the micrograph. Two types of pits are found: circular pits with a flat bottom and pits with very anisotropic shapes (rectangular and triangular). It is believed that the rectangular shape is caused by the anisotropy of the interaction between a nodule and the electric field at $65^{\circ}$ incidence angle. The circular pits are thought to be caused by very small absorption centers.
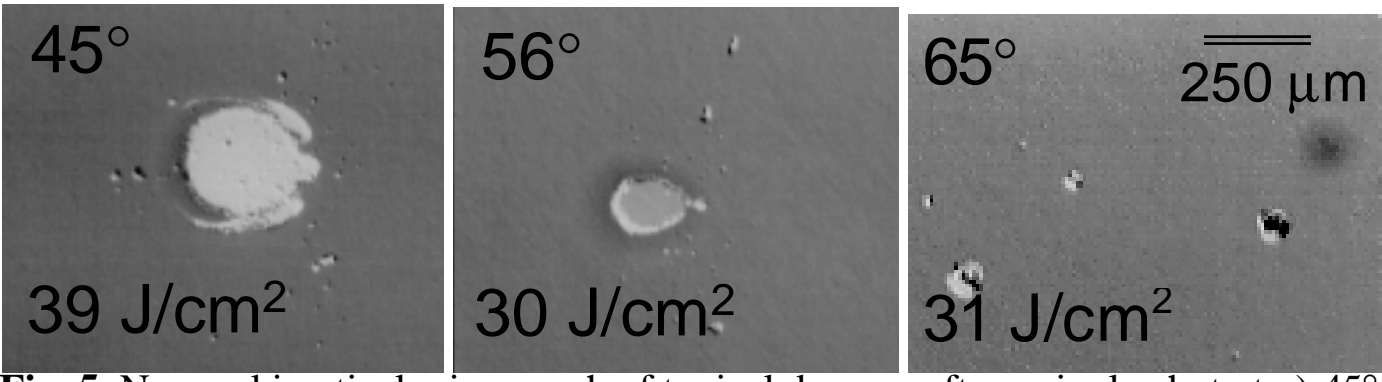

Fig. 5: Nomarski optical micrograph of typical damage after a single shot at a) $45^{\circ}$, b) $56^{\circ}$, and c) $65^{\circ}$ at 39,30 , and $31 \mathrm{~J} / \mathrm{cm}^{2}$, respectively.
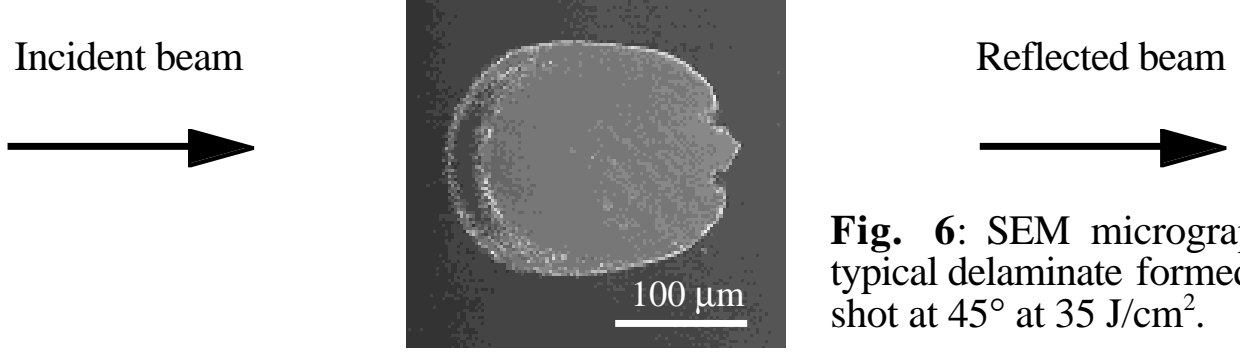

Fig. 6: SEM micrograph of a typical delaminate formed after a shot at $45^{\circ}$ at $35 \mathrm{~J} / \mathrm{cm}^{2}$.

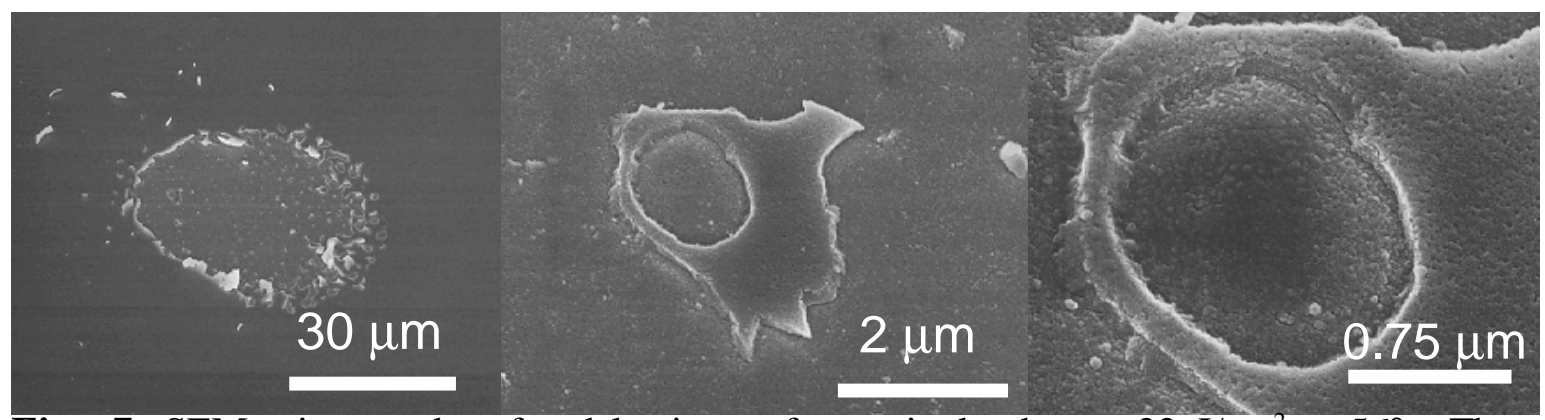

Fig. 7: SEM micrographs of a delaminate after a single shot at $22 \mathrm{~J} / \mathrm{cm}^{2}$ at $56^{\circ}$. The micrographs in the center and on the left are higher magnification images of the region where delamination seems to have initiated. The micrographs clearly show that only the silica top layer was removed and that the surrounding areas are covered with debris. 

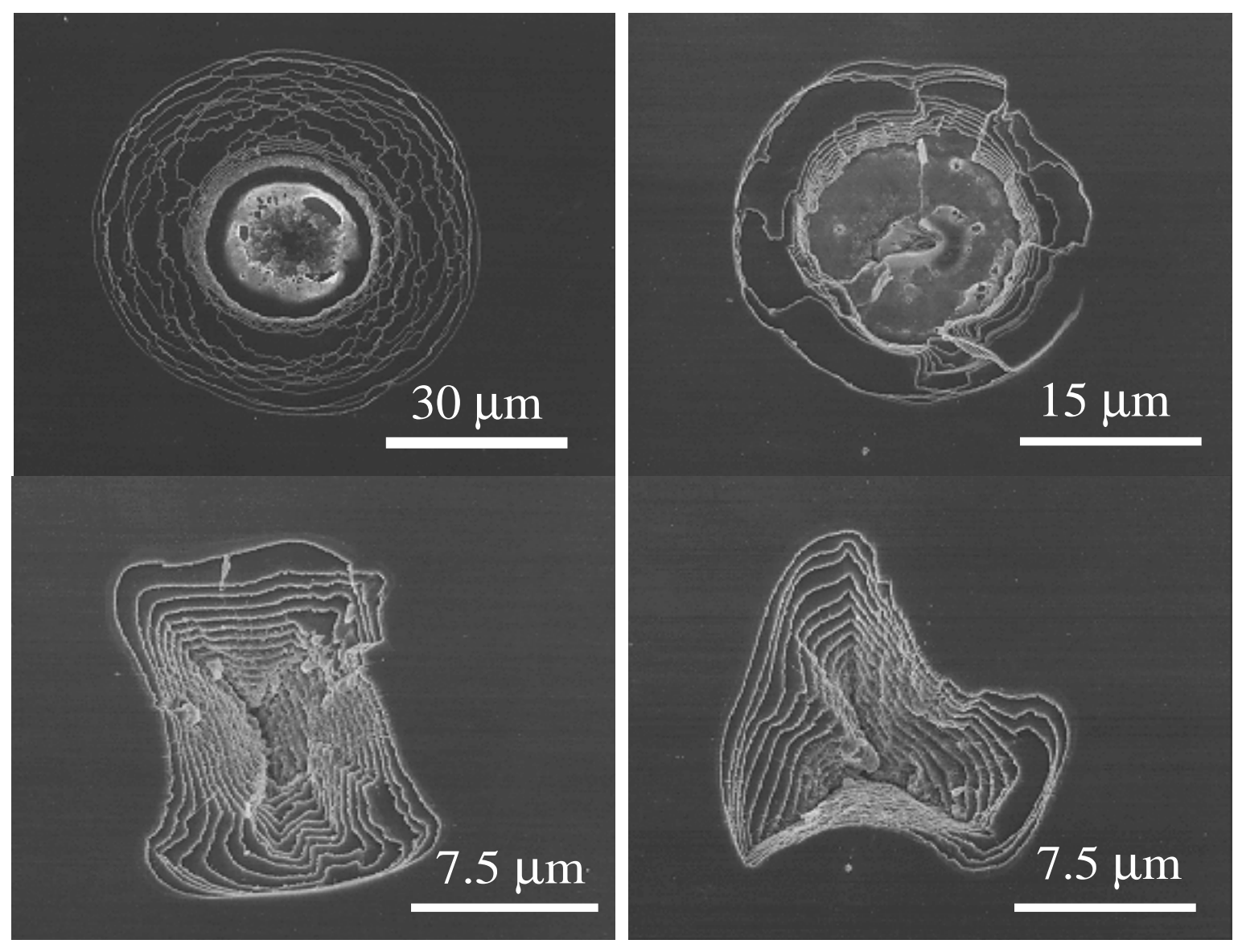

Fig. 8: SEM micrographs of the various pit morphologies after a single shot at $31 \mathrm{~J} / \mathrm{cm}^{2}$ at $65^{\circ}$. The anisotropy of the pits indicates that the electric field interaction with defects is quite anisotropic.

\subsection{Damage thresholds:}

The maximum damage size was plotted as a function of peak fluence for each type of damage morphology (see Fig. 9) in order to quantify the behavior of specific types of damage. A total number of 30,50 , and 20 sites were tested at $45^{\circ}, 56^{\circ}$ and $65^{\circ}$, respectively. Figure 9c) shows that for $65^{\circ}$ angle of incidence, the delaminate morphology has disappeared. On the other hand, the pit size has drastically increased and the number of pits at $65^{\circ}$ is much larger (see Fig. 5c). Comparison between Fig. 9a) and 9b) also shows for a similar fluence a reduction in delaminate size between $45^{\circ}$ to $56^{\circ}$ incidence. This can be explained by the reduction in stress in the outer layer between these two angles of incidence (see Fig. 4).

As mentioned earlier, the study of damage growth of the various damage morphologies ${ }^{16}$ showed that small pits and flat bottom pits as well as scalds do not usually grow upon repetitive illumination below $30 \mathrm{~J} / \mathrm{cm}^{2}$. On the other hand, once formed, delaminates and large pits tend to grow very rapidly to catastrophic proportions with subsequent shots. From the absence of delaminates at $65^{\circ}$, it was hoped that the polarizers could be conditioned at $65^{\circ}$ so that the damage sites could be stabilized without initiating delaminates. Unfortunately, the formation of very large and deep pits which were found to potentially grow during repetitive irradiation, prevented this non-use angle type of laserconditioning from being beneficial to the polarizer's survivability. 
a) $45^{\circ}$

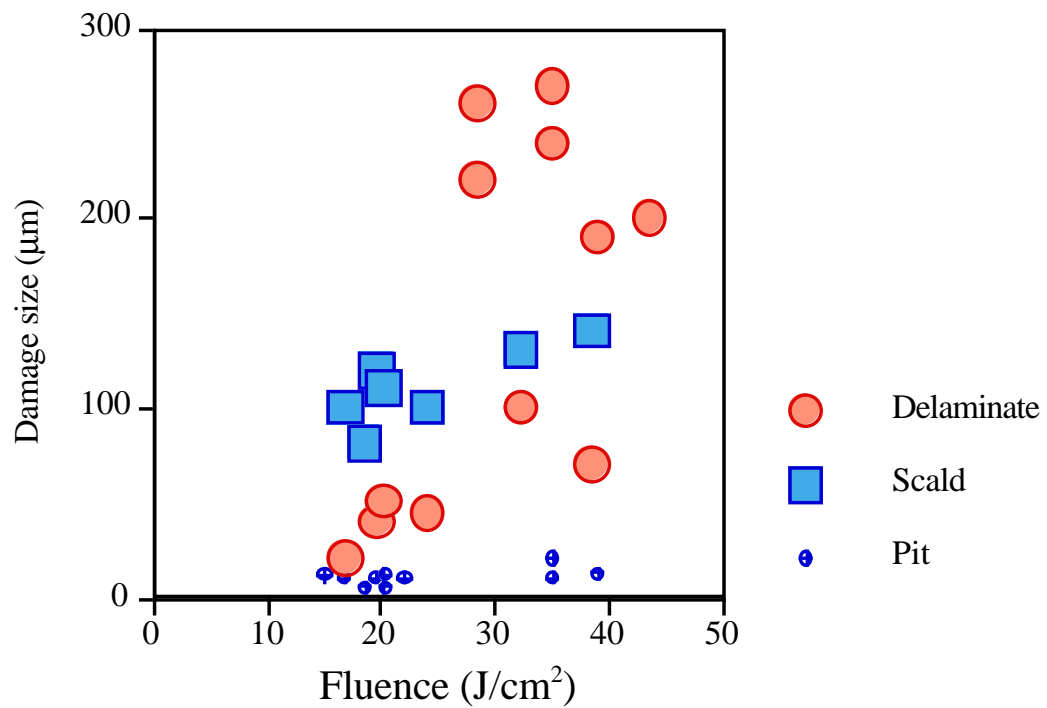

b) $56^{\circ}$

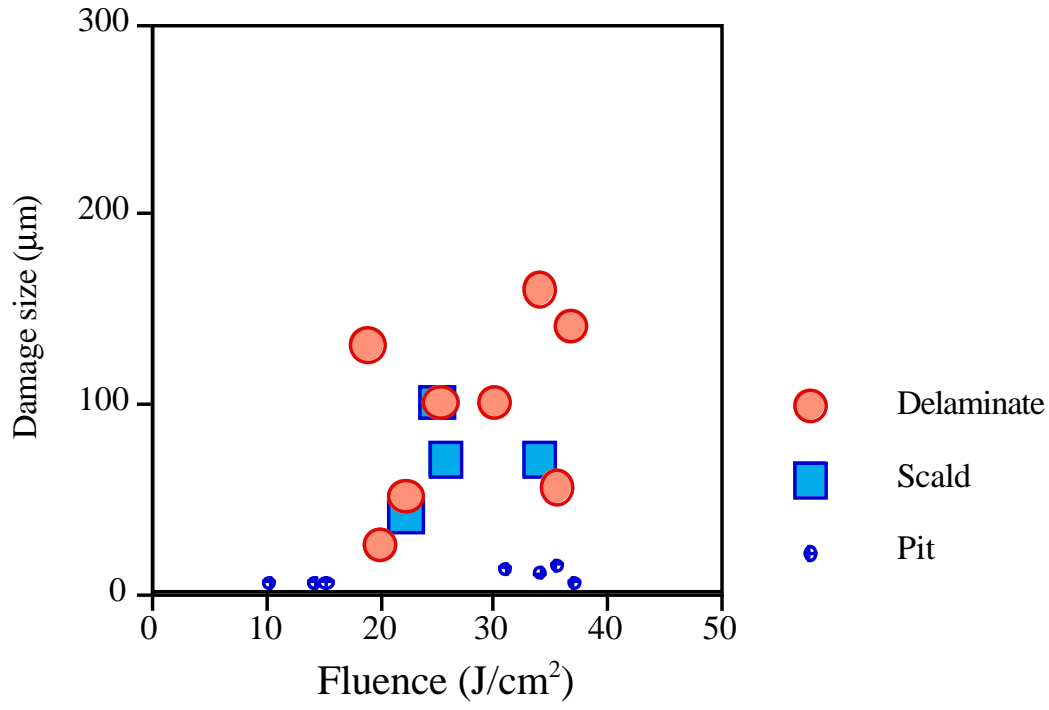

c) $65^{\circ}$

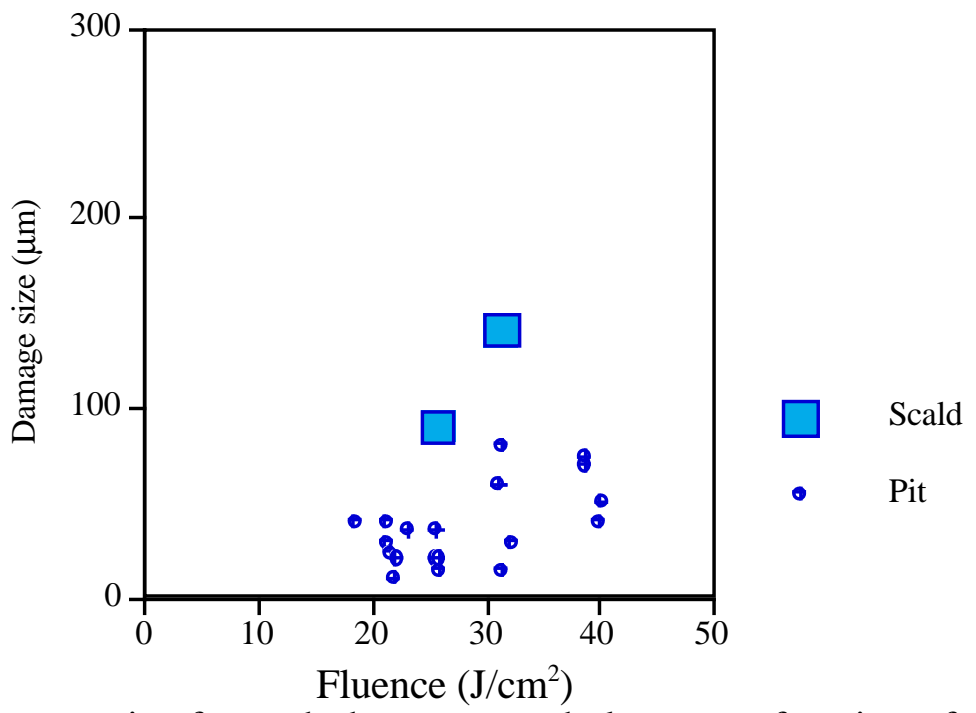

Fig. 9: Damage size for each damage morphology as a function of fluence after a single shot at a) $45^{\circ}$, b) $56^{\circ}$ and c) $65^{\circ}$. 
As discussed earlier, the relationship between electric field distribution, (and temperature or stress profile) and damage morphology is still not fully understood. However, Fig. 4 shows that the change in principal stress in the first layer pair is lowest at $65^{\circ}, 56^{\circ}$, and $45^{\circ}$, respectively. Since e-beam evaporated silica and hafnia are under intrinsic compressive and tensile stress respectively, the thermal stress can add to the stress difference between two adjacent layers and lead to higher potential for interfacial failure. Furthermore, Fig. 4 clearly shows that the stress intensity peaks deeper in the stack and that the stress decays less quickly at $65^{\circ}$. This has the potential for activating weak points that are deeper in the multilayer and may explain the formation of deep and large pits as well as their increase in number. Since more volume is affected, more defects are likely to be active and a larger number of damage sites should be found.

\section{CONCLUSION}

Hafnia-silica multilayer polarizers designed to operate at $1064 \mathrm{~nm}$ at Brewster's angle $\left(56^{\circ}\right)$ were tested with a 3 -ns laser pulse at $45^{\circ}, 56^{\circ}$, and $65^{\circ}$ incidence angle. The characterization of the morphology of the laser-induced damage showed the four commonly found damage morphologies (pit, flat bottom pit, scald, and outer layer delamination). The occurrence of the different damage morphologies was found to be strongly sensitive to the angle of incidence of the laser beam. In particular, massive delamination observed at $45^{\circ}$ and $56^{\circ}$ incidence, did not occur at $65^{\circ}$. Instead, the number and size of the pits were found to increase drastically at $65^{\circ}$. The damage morphology and the possible advantages of offuse angle laser conditioning were considered. The results showed that while some defects (such as delaminates) could be eliminated by conditioning at $65^{\circ}$, other types of defects (such as large and deep pits) initiated catastrophic failure.

Testing the polarizers under such conditions also allowed to artificially vary the electric field distribution in the multilayer as well as the temperature and stress profiles. The thermal mechanical response of the multilayer during laser illumination was modeled to understand the relationship between damage morphology, electric field peak locations, and maximum thermal stress gradients. The results showed that while this simple model cannot quantitatively explain all damage morphologies(e.g. scalds), the calculations are in general agreement with experimental observations which indicate that the stress in the outer hafnia layer is higher at $45^{\circ}$ and $56^{\circ}$, increasing the potential for interfacial delamination. Also, the electric field at $65^{\circ}$ penetrates deeper into the multilayer and seems to cause the formation of

deeper and larger pits. Further work should be conducted to better understand the role of plasmas on damage, particularly to explain surface scald formation and delaminate damage shape.

\section{ACKNOWLEDGMENTS:}

This work was performed under the auspices of the U.S. Department of Energy by Lawrence Livermore National Laboratory under Contract W-7405-Eng-48, the Laser Mégajoules project (CEA-DAM-DLP), and the French Ministry of Defense (Group IV). The authors express their gratitude to Jim Yoshiyama for carrying out the SEM characterization of the films and to Nicole Molau for formatting the electric field data. Many thanks are finally expressed to Dr. Jean Hue, and Lynn Sheehan for their comments and suggestions on the manuscript. 


\section{REFERENCES}

1. R. R. Austin, R. Michaud, A. H. Guenther, and J. Putman, "Effects of structure, composition, and stress on the laser damage threshold of homogeneous and inhomogeneous single films and multilayers", Appl. Optics 12, 665 (1973).

2. T. W. Walker, A. H. Guenther, C. G. Fry, and P. Nielson, "Pulsed damage thresholds of fluoride and oxide thin films from $0.26 \mu \mathrm{m}$ to $1.06 \mu \mathrm{m}$ ", Laser-Induced Damage in Optical Materials, NBS SP 568, 405 (1979).

3. A. F. Turner, "Ruby laser damage thresholds in evaporated thin films and multilayer coatings", Laser-Induced Damage in Optical Materials, NBS SP 356, 119 (1971).

4. D. M. Spriggs, P. A. Sermon, M. S. W. Vong, and Y. Sun, "Laser damage studies of tantala and zirconia sol gel coatings", Laser-Induced Damage in Optical Materials, SPIE 2714, 537 (1995).

5. J. H. Apfel, "Further studies of the role of electric field strength in laser damage of dielectric layers", Laser-Induced Damage in Optical Materials, NBS SP 509, 251 (1977).

6. B. E. Newnam, D. H. Gill, and G. Faulkner L. J. Jolin, "Influence of standingwave fields on the laser damage resistance of dielectric films", Laser-Induced Damage in Optical Materials, NBS SP 435, 254 (1975).

7. B. E. Newnam, S. R. Foltyn, D. H. Gill, L. J. Jolin, "Angular dependence of multilayer-reflector damage thresholds", Laser-Induced Damage in Optical Materials, NBS SP 727, 342 (1984).

8. J. D. Boyer, S. R. Foltyn, S. R. Mauro, and V. E. Sanders, "Angular dependence of thin-film dielectric coating damage thresholds revisited", Laser-Induced Damage in Optical Materials, NIST SP 801, 417 (1989).

9. S. S. Wiseall and D. C. Emmony, "A laser damage facility in the ultra-violet", Laser-Induced Damage in Optical Materials, NBS SP 669, 102 (1982).

10. G. Pfeifer, E. Erben, G. Reisse, and B. Steiger, "Damage morphologies and causes of laser-induced damage of thin oxide films at $248 \mathrm{~nm}$ ", Laser-Induced Damage in Optical Materials, SPIE 2428, 377 (1994).

11. E. S. Bliss, "Pulse duration dependence of laser damage mechanisms", OptoElectronics 3, 99 (1971).

12. K. H. Guenther, T. W. Humpherys, et al., "1.06 $\mu \mathrm{m}$ laser damage of thin film optical coatings: a round robin experiment involving various pulse lengths and beam diameters", Appl. Optics 23, 3743 (1984).

13. C. R. Giuliano and D. Y. Tseng, "Laser-induced surface damage in proustite $\left(\mathrm{Ag}_{3} \mathrm{AsS}_{3}\right)$ at $1.06 \mu \mathrm{m}$ and $0.694 \mu \mathrm{m}$ ", Laser-Induced Damage in Optical Materials, NBS SP 387, 239 (1973).

14. K. Mann, H. Gerhardt, G. Pfeifer, B. Steiger, and F. Wenzel, "Influence of the laser pulse length and shape on the damage threshold of ultraviolet optics", Laser-Induced Damage in Optical Materials, SPIE 1624, 436 (1991).

15. S. V. Garnov, S. M. Klimentov, A. A. Said, and M. J. Soileau, "Laser damage of HR, AR-coatings, monolayers and bare surfaces at $1064 \mathrm{~nm}$ ", Laser-Induced Damage in Optical Materials, SPIE 1848, 162 (1992).

16. F. Y. Génin, C. J. Stolz, and M. R. Kozlowski, "Growth of laser-induced damage during repetitive illumination of $\mathrm{HfO}_{2}-\mathrm{SiO}_{2}$ multilayer mirror and polarizer coatings", in these proceedings.

17. F. Y. Génin and C. J. Stolz, "Morphologies of laser-induced damage in hafniasilica multilayer mirror and polarizer coatings", Third International Workshop on Laser Beam and Optics Characterization, SPIE 2870, 439 (1996).

18. W. H. Lowdermilk, D. Milam, and F. Rainer, "Damage to coatings and surfaces by $1.06 \mu \mathrm{m}$ pulses", Laser-Induced Damage in Optical Materials, NBS SP 568, 391 (1979). 
19. C. K. Carniglia, J. H. Apfel, G. B. Carrier, and D. Milam, "TEM investigation of effects of a barrier layer on damage to $1.064 \mu \mathrm{m}$ AR coatings", Laser-Induced Damage in Optical Materials, NBS SP 541, 218 (1978).

20. C. K. Carniglia, J. H. Apfel, T. H. Allen, T. A. Tuttle, W. H. Lowdermilk, D. Milam, and F. Rainer, "Recent damage results on silica/titania reflectors at 1 micron", Laser-Induced Damage in Optical Materials, NBS SP 568, 377 (1979).

21. C. Stolz, F. Y. Génin, T. Reitter, R. Bevis, M. vonGunten, and J. Hue, "Effect of silica overcoat thickness on the laser damage morphology in $\mathrm{HfO}_{2} / \mathrm{SiO}_{2}$ Brewster's angle polarizers at $1064 \mathrm{~nm} "$, in these proceedings.

22. A. J. Morgan, F. Rainer, F. P. DeMarco, R. P. Gonzales, M. R. Kozlowski, and M. C. Staggs, "Expanded damage test facilities at LLNL", Laser-Induced Damage in Optical Materials, NIST SP 801, 47 (1989).

23. H. A. Macleod, "Macleod thin-film design software", Tucson, AZ, 1983.

24. R. H. Sawicki, C. C. Shang, and T. L. Swatloski, "Failure characterization of nodular defects in multi-layer dielectric coatings", Laser-Induced Damage in Optical Materials, SPIE 2428, 333 (1994).

25. J. F. DeFord and M. R. Kozlowski, "Modeling of electric-field enhancement at nodular defects in dielectric mirror coatings", Laser-Induced Damage in Optical Materials, SPIE 1848, 455 (1992).

26. A. B. Shapiro, A. L. Edwards, "TOPAZ2D Heat Transfer Code Users Manual and Thermal Property Data Base", LLNL, UCRL-ID-104558, May 1990.

27. B. Engelmann, "NIKE2D: A Nonlinear, Implicit, Two-Dimensional Finite Element Code for Solid Mechanics, User Manual", LLNL, UCRL-MA-105413, April 1991. 


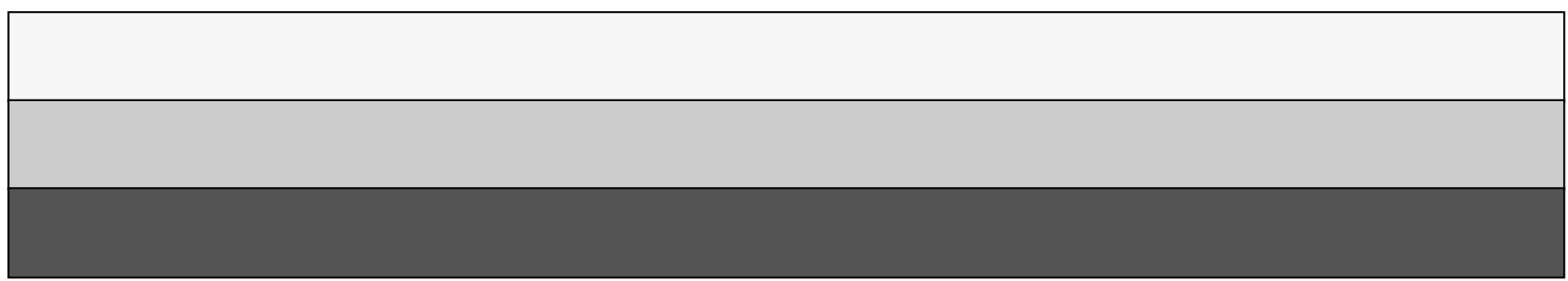

